\title{
Research on Demand Management of Clothing Commodity Planning
}

\author{
Yinjia Zhang ${ }^{1, a, *}$ \\ ${ }^{1}$ Quanzhou Normal University, Quanzhou 362000, China \\ a397398447@qq.com \\ *corresponding author
}

Keywords: commodity planning; consumer demand; demand management

\begin{abstract}
Commodity planning is the consumer's potential demand and desire and other abstract elements with specific goods show, planning the market activities, precisely the consumer demand through the merchandise plan into the enterprise sales activities. Therefore, planning in the garment production process in a leading part of the successful enterprises in a strategic position. At present, the domestic garment enterprises are still immature in commodity planning. This paper analyzes the demand problem of garment commodity planning, and expounds the five stages of demand management, including demand acquisition, demand consolidation, demand transfer, demand analysis and demand verification. And analyzes the standard of excellent demand management, so as to provide reference and guidance for the garment enterprises to carry out commodity planning.
\end{abstract}

\section{Introduction}

Brand development is the most critical is to improve the brand's market share, and maintain steady growth, and this one of the key is to accurately grasp the psychological needs of consumers, flexible response to changes in the market environment. As the basis for brand building and development of commodity planning is based on the target consumer to meet the living habits, consumer aspirations and self-realization of the desire. However, there are still many domestic brands do not really understand the meaning of commodity planning and clothing products in the development process of the irreplaceable strategic position. Which led to these clothing brands although well-known, but the market size is difficult to upgrade.

Planning is an integral part of the marketing mix. With the change of the times, the management policy of garment enterprises is shifted from production-oriented to market-oriented, and the non-price competition among enterprises is paid more and more attention. An effective means is to carry out excellent planning.

Commodity planning, referred to as MD (merchandising), defined as: enterprises to achieve sales targets, using the most favorable places, time, price, quantity (quality), the specific goods to the market for planning and management.

Fashion merchandising refers to a series of activities aimed at the potential needs, desires and expectations of apparel consumers, the planning of apparel products and the realization of self-actualized clothing products.

\section{Analysis on the Demand of Clothing Commodity Planning}

\subsection{An Analysis of the Current Situation of Commodity Planning in China's Garment Enterprises}

Although the garment industry has the characteristics of labor-intensive and low entry threshold, although the rapid development of China's garment industry, but in the global clothing commodity chain in the most basic processing sewing, high labor costs, small value-added products, poor 
environmental friendliness, And the problem of overcapacity is becoming more and more obvious. Most of the garment enterprises are facing the key to transformation and upgrading, and meet the needs of the market planning has become one of the most important core competitiveness of garment enterprises.

At present, the planning of domestic enterprises can be divided into three categories: First, product planning, the second is marketing planning, the third is the brand planning. One and two are not really the meaning of the clothing commodity planning, and a small part of the brand planning to do business is only in its first stage. In the final analysis, management's awareness of the importance of planning has not yet reached its height. Most enterprise management only from the surface of the market economy, spend great efforts to market development, marketing and public relations to improve the broadening of the commodity planning, ignoring the source. Mature product development should be based on product planning based on the product design, production and so on the back-end sales. The sales of a product is largely determined by its correctness in the direction of commodity planning, and the focus of commodity planning is to grasp the needs of customers.

$\mathrm{Y}$ company, is a single production from the brand underwear company, its brand in the industry also called the top, but faced with can not occupy more of the market, can not have the brand loyal customers embarrassing bottleneck. So spent heavily from their competitors to dig design director, but after two years of running, still no effect. The reason is that its high-level lack of attention to the planning department, planning department in name only, failed to assume the overall responsibility for the development of the overall product development program, the marketing department to replace the Department of Planning in the product development process control product design, pricing policy and Marketing means of absolute life and death. In the final analysis is the enterprise executives have not yet get rid of a single custom business ideas, only focus on using sales data to guide the development of new products, can not be aware of the advantages of planning to give full play to product development, which is the crux of the rapid development of enterprises.

\subsection{Analysis of the Demand of Clothing Commodity Planning}

Clothing is the object of the service, so the object of clothing goods planning is not clothing, but the clothing of the wearer --- people. The focus of planning is on the extraction, analysis, management and transformation of requirements. In the above planning process, the actual operation of the main problems often encountered often is the analysis of information to the concept of this part of the transmission, how to collect the scattered and abstract information effectively into the design concept This is troubled Many clothing enterprises stubborn problem, and the reason is that most companies, although the principles and processes to follow the plan, but did not really understand the essence of planning-the solution to the needs of the problem. As shown in Fig. 1, the lack of available and timely market demand information is leading to product redirection and product failure is an important factor, but also most of the clothing business development cycle, repeated changes in the reasons.

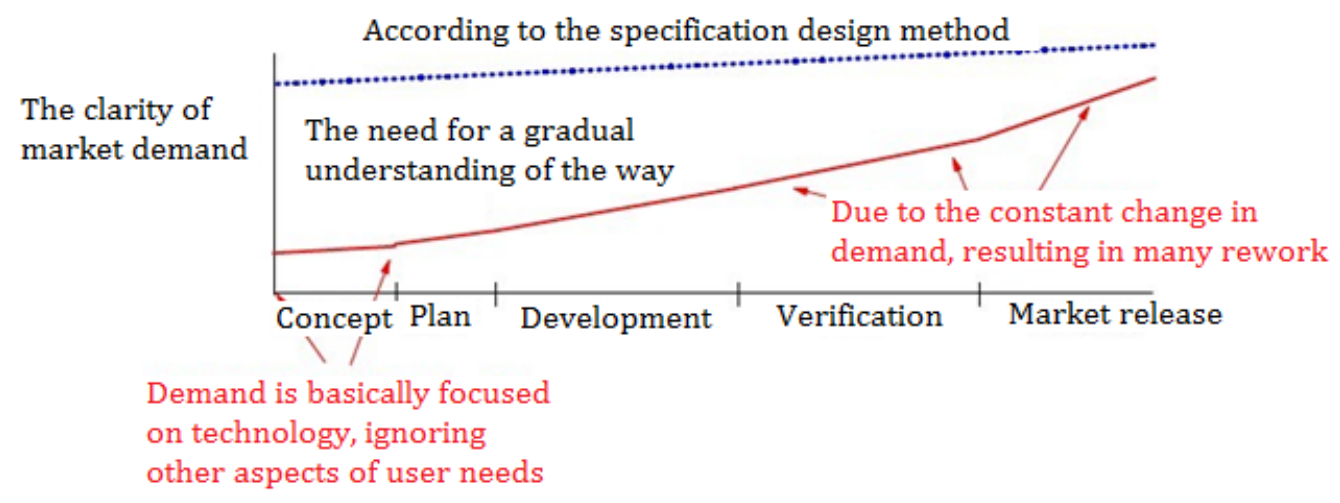

Fig. 1 clothing business needs to grasp the curve

In the actual clothing merchandise planning process, the demand for the performance of the customer in the eyes of the cloud, but when you put this cloud to the original demand for the person, 
she may say "In fact, I do not want this "Then you will give the" Elegant Clouds "once again to the demander, she may say," I want the fit of the elegant clouds, "he said. "... ... this repeated, the final solid color silk tail skirt is probably the real demand. In other words, with the different versions of the "cloud" was delivered, but also inspired to constantly refine and clear all kinds of ideas and requirements.

In this way, at the beginning of the project to clear a recognized "cloud" is extremely important. Y company, for example, its new product development failed to timely delivery of about $40 \%$ of the reason is that the concept of setting the stage of repeated changes, and modify the reason is constantly entangled in the concept and demand is the corresponding issue. This not only led to the extension of the development cycle, but also increased development costs, reducing new profits.

\section{Garment Business Needs Management Methods}

\subsection{Planning Requirements Management Approach}

One of the ways to solve the problem of demand for garment enterprises is to manage demand. The requirements of the process include: demand collection, demand consolidation, demand delivery, demand analysis, demand validation.

(1) Demand collection

Requirements include customer requirements (customer requirements and services) and product requirements (product-provided functionality and services), and product requirements are often a subset of customer requirements below. Demand for a wide range of acquisition channels, mainly primary information and second-hand information. First-hand information includes marketing activities, sales activities, user activities; second-hand information from public information, business partners, professional data. See Fig. 2.

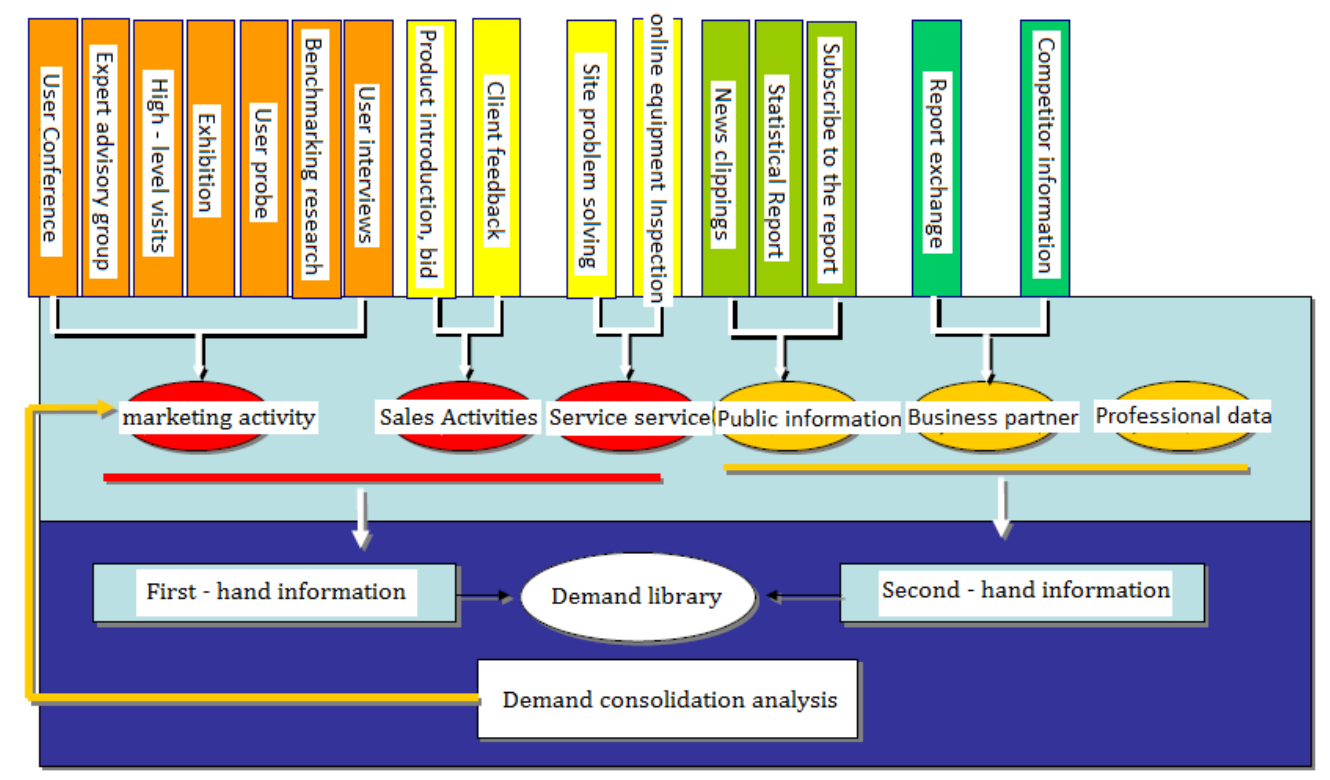

Fig. 2 Acquisition of customer needs

Different acquisition methods have different effects, with direct effect is the user conference and expert consultants, and the demand probe, user interviews, high-level technical exchanges, product trials, on-site support and after-sales feedback is only brief introduction effect. Most of the acquisition methods are only short-term, for the current effectiveness. Expert consultants and high-level technical exchanges of the best, in the time range and product range have a better effect, with long-term and foresee the future, for the clothing business is the most effective demand collection method. 


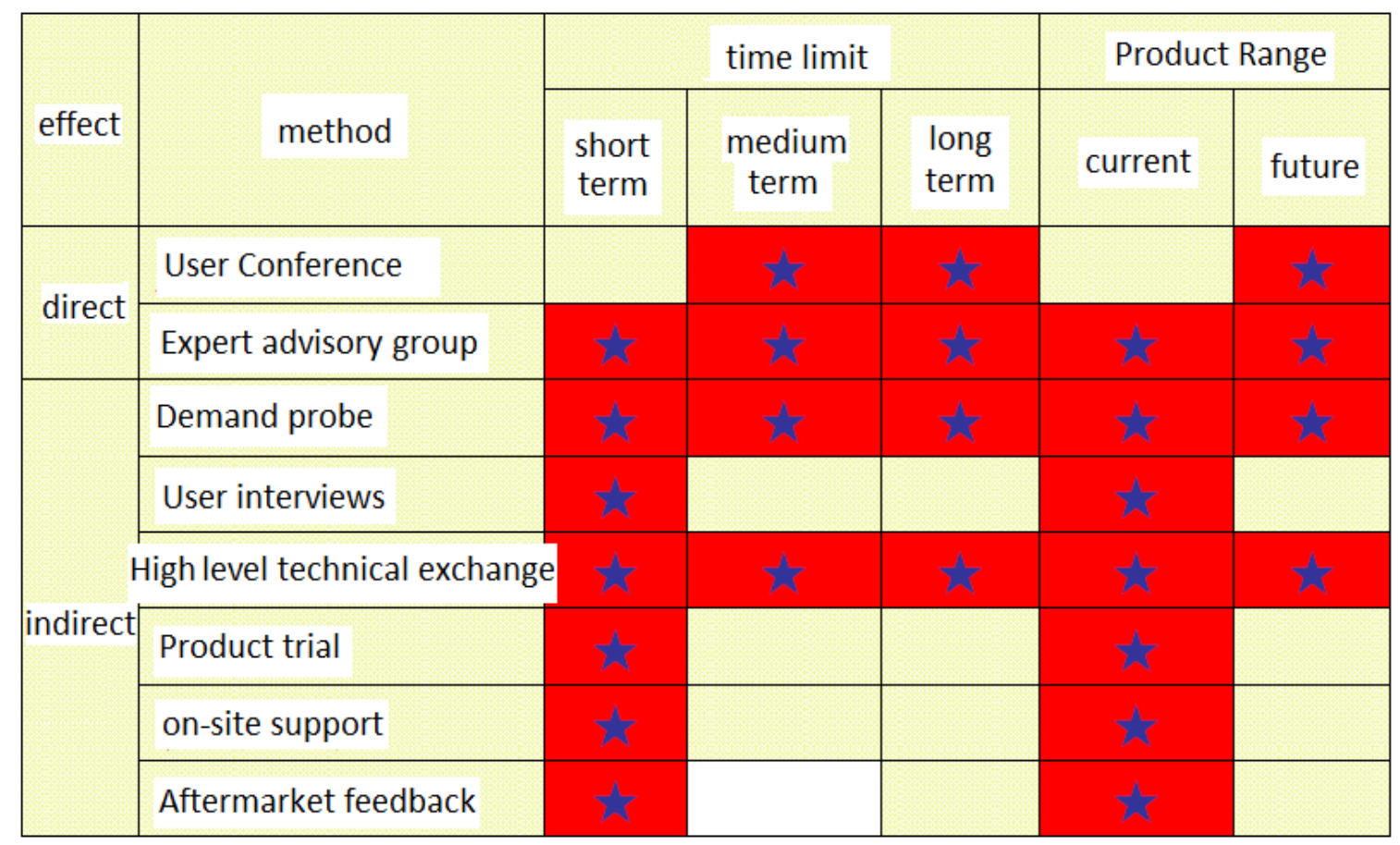

Fig. 3 Features of the requirements acquisition method

In the demand acquisition process to pay attention to the importance of listening. To listen to, and can not be in the collection process to sell their own ideas; to hear to be confirmed to ensure that the full understanding of each other's meaning; performance "ignorance" point, so that the other as detailed description and examples; focus on people Expectations rather than a problem; pay attention to listen to inconsistencies.

The acquisition of requirements is a process that needs to be clarified by describing the needs that are collected. Descriptions are critical to the business, and good demand description is the origin and key to demand management. The five principles of demand description include:

1. Identify what the product must do, not what should it do

2. Describe the demand in detail as stated in the original data

3. Use affirmative sentences instead of negative sentences

4. The demand for the expression of the product attributes, features

5. Avoid using must and should

In the actual operation of the enterprise, the collection of demand should not be limited to the scope of the responsibilities of the planning staff, but should play the advantages of various departments, all aspects of real-time demand collection. The recommended practice is to construct a routine demand acquisition mechanism. Such as:

1. Build demand to collect IT systems

2. Form a demand collection reporting mechanism

3. Set up a team of needs analysis and analysis

4. And staff qualifications, performance linked

5. Control nerve endings (travel, exhibition, tender, etc.)

(2) the need for finishing

Will be collected to meet the needs of a certain category of classification, the demand for each category called the demand group, the main classification methods are:

Priority classification: mandatory, non - mandatory, guidance, reference

Product Lifecycle Stage: Development, Manufacturing, Testing, Shipping, Installation, Operation, Maintenance, Recycling

Source classification: contracts, norms, corporate strategy, rules and regulations, agreements, standards 
(3) the transfer of demand

In the process of demand delivery, the main responsibilities of the company-level demand management are: screening, finishing the needs of the demand management library; establishing the relationship between demand and product; determining the demand output interface unit, responsible person, processing cycle; management requirements processing status. The main responsibilities of the marketing department are: to help the company-level demand management staff to meet the needs; according to the input needs analysis of market opportunities, output (rejection, acceptance); if the market opportunity to determine the output to the product development department. The main responsibilities of the product department are: to assist the company-level demand management to meet the needs; according to the input needs to determine the distribution of the line (cross product line, product line, a single product); analysis of demand, according to departmental capacity, product progress to determine the demand Adopt, reject, hold, and feed back the demand state to the company-level demand manager. The responsibility of the demand-providing department is to enter the requirements according to the requirements of the template; explain and clarify the question of the demand management department; cooperate with the product department to verify and refine the demand. Fig. 4 shows the demand for delivery.

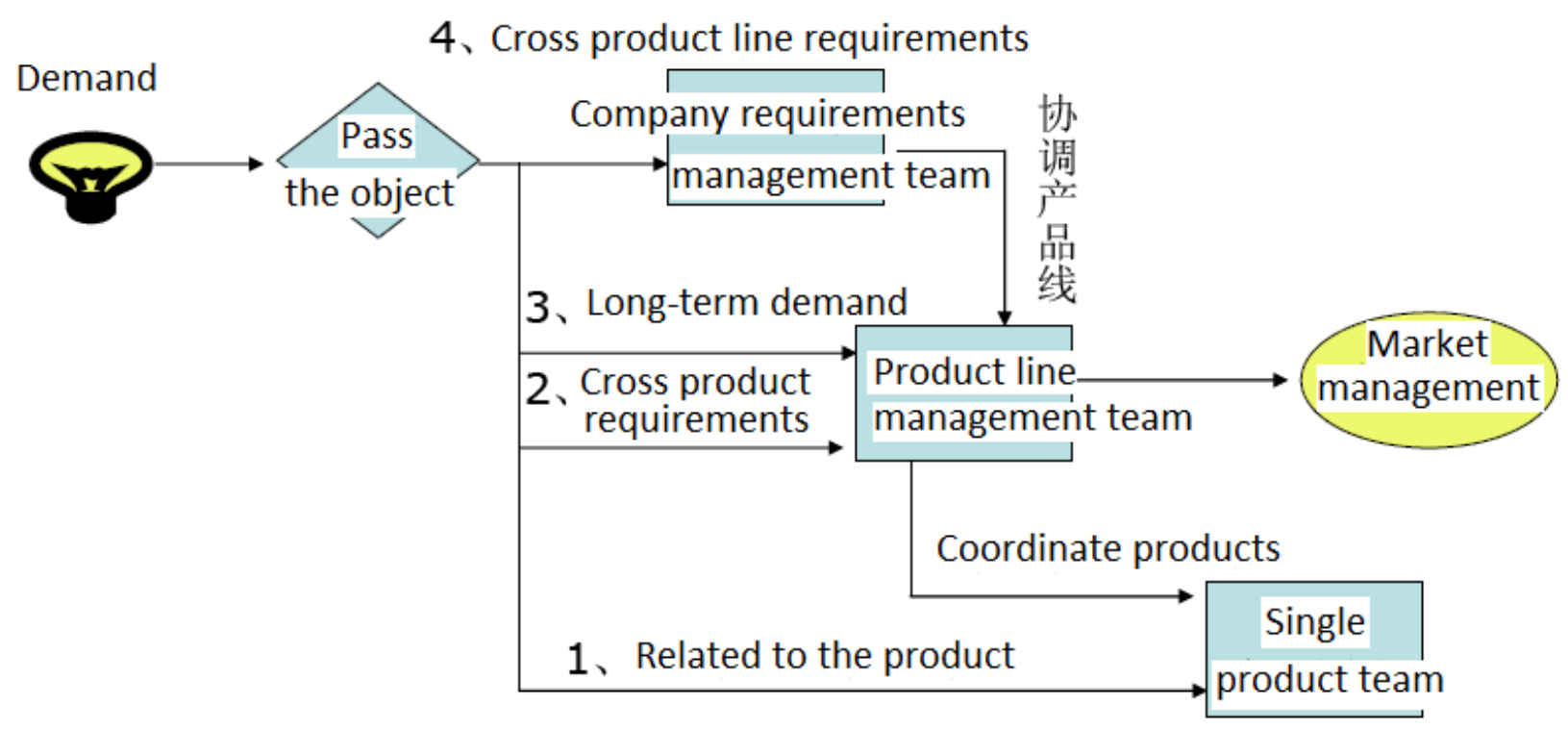

Fig. 4 Demand delivery

(4) Analysis of needs

Demand analysis is a recurring process, always throughout the product development process, usually using \$ APPEALS model for demand analysis. The \$ APPEALS model focuses on the choice of target groups in the purchase of competing products by analyzing product prices, availability, packaging, performance, ease of use, degree of assurance, life cycle costs, and social acceptability. \$ APPEALS model of the elements of the analysis of the object shown in Table 1. 
Table 1 Customer \$ APPEALS Model Feature Description

\begin{tabular}{|c|c|}
\hline $\begin{array}{l}\text { \$ APPEALS } \\
\text { Elements }\end{array}$ & Customer \$ APPEALS Element Description \\
\hline $\begin{array}{c}\$ \\
\text { price }\end{array}$ & $\begin{array}{l}\text { This element reflects the customer's price for a satisfactory product / } \\
\text { delivery desired to pay. With this standard to ask the supplier, from the } \\
\text { actual and feel these two aspects to consider the customer can accept the } \\
\text { purchase price. Will include the following data to assess: technology, } \\
\text { low cost manufacturing, materials, labor costs, manufacturing costs, } \\
\text { experience, degree of automation, simplicity, manufacturability and so } \\
\text { on. }\end{array}$ \\
\hline $\begin{array}{c}\text { A } \\
\text { availability }\end{array}$ & $\begin{array}{l}\text { This element describes the customer's easy and efficient purchase } \\
\text { process (for example, letting the customer have his own "way"). Use this } \\
\text { standard to ask the supplier to consider the level of excellence } \\
\text { throughout the purchase process, including pre-sale technical support } \\
\text { and demonstration, purchase channel / supplier selection, delivery time, } \\
\text { customer customization and so on. }\end{array}$ \\
\hline $\begin{array}{c}\mathrm{P} \\
\text { package }\end{array}$ & $\begin{array}{l}\text { This element describes the desired design quality. Performance and } \\
\text { appearance of visual features. Use this standard to ask suppliers, to } \\
\text { consider the customer on the shape, design and other views, as well as } \\
\text { the contribution of these attributes to the degree of contribution. The } \\
\text { consideration of packaging should include design, modularity, } \\
\text { integration, structure, color, graphics, process design and so on. }\end{array}$ \\
\hline $\begin{array}{c}\mathrm{P} \\
\text { performance }\end{array}$ & $\begin{array}{l}\text { This element describes the desired functionality and characteristics of } \\
\text { this delivery. When using this standard to request a supplier, consider } \\
\text { the performance of the desired function and characteristics of the } \\
\text { product from both the actual and the senses. How does the product } \\
\text { work? Does the product have all the necessary and desirable features? } \\
\text { Does it provide higher performance? From the customer point of view, } \\
\text { such as speed, power, capacity and so on. }\end{array}$ \\
\hline $\begin{array}{c}E \\
\text { easy to use }\end{array}$ & $\begin{array}{l}\text { This element describes the easy-to-use properties for delivery. When } \\
\text { using this standard to request the supplier, consider the customer's } \\
\text { consideration of the product in terms of comfort, learning, document, } \\
\text { support, humanization, display, feeling input / output, interface, } \\
\text { "intuitive" and so on. }\end{array}$ \\
\hline $\begin{array}{c}\text { A } \\
\text { assure }\end{array}$ & $\begin{array}{l}\text { This element usually reflects the assurance of reliability in terms of } \\
\text { safety and quality. When using this standard to ask the supplier, consider } \\
\text { how the customer evaluates the entire product in a predictable } \\
\text { environment with respect to reducing his / her focus on the identified } \\
\text { performance? This may include assurance, identification, redundancy } \\
\text { and strength. }\end{array}$ \\
\hline $\begin{array}{c}\mathrm{L} \\
\text { life cycle cost }\end{array}$ & $\begin{array}{l}\text { This element describes the owner's cost of using the entire lifecycle. Use } \\
\text { this standard to ask suppliers to consider installation costs, training, } \\
\text { services, supply, energy efficiency, value depreciation, and processing } \\
\text { costs. }\end{array}$ \\
\hline $\begin{array}{c}\text { S } \\
\text { social influence }\end{array}$ & $\begin{array}{l}\text { This element describes the other effects that affect the purchase } \\
\text { decision. When using this element to ask the supplier, consider how the } \\
\text { oral decision, third party expert evaluation, consultant's report and } \\
\text { opinion, image, government or industry standards, regulations, social } \\
\text { recognition, legal relationship, product obligations, etc. The promotion } \\
\text { of the role. }\end{array}$ \\
\hline
\end{tabular}

\$ APPEALS model of the analysis process includes: set the hierarchy, set the weight of the criteria, set the evaluation criteria, judge the product performance and generate graphical reports.

Fig. 5 shows the \$ APPEALS model used by the analysis of the spider map, through the spider can be intuitive to understand the most influential factors and needs, so as to extract the relevant demand group for product portfolio. 


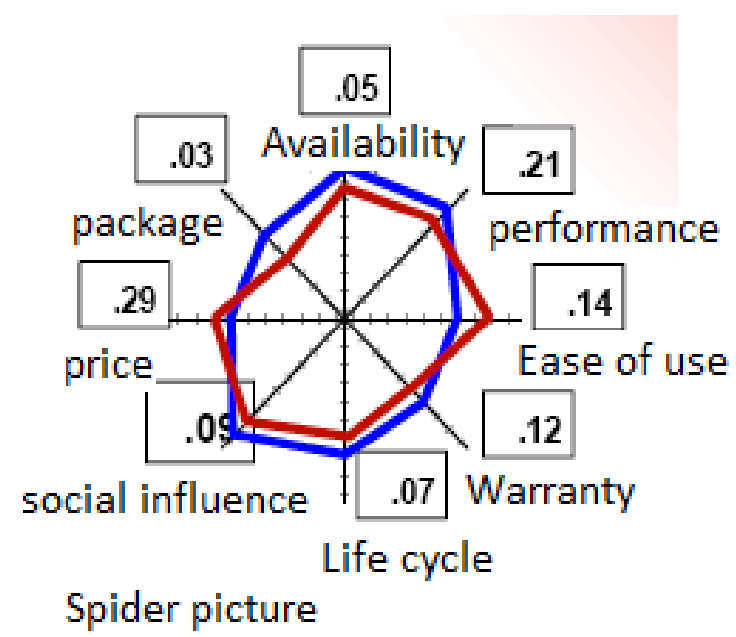

Fig. 5 \$ APPEALS model analysis

(5) Validation of requirements

The collected needs are not adopted, but need to be verified by the relevant departments before they can be included in the demand library. Requirements validation includes functional architecture integrity verification, physical architecture integrity verification, functional and performance metrics, and satisfaction of the constraints to determine the preferred design. For the listed products should also be sales data, customer feedback and other tracking research to verify the extent of the realization of demand, so as to guide the new product development process of demand management.

\subsection{Criteria for good demand}

(1) Integrity

Demand must be complete in order to be easy to use and trace back to its source. Each requirement must be a complete description of the function to be delivered, to obtain a complete demand decomposition structure, in a certain sense, this can facilitate the verification of late requirements.

(2) Correctness

Each requirement must accurately state its function to be developed. The correct judgment is based on the source of the demand and its degree of support for the project objectives. Therefore, the demand record should be able to trace back to its source and its supporting business use case , Its upper and lower relations in the demand decomposition structure. The customer's participation plays a decisive role in determining the correctness of the demand. Which requires user needs consistent with business needs, and functional requirements consistent with the needs of users.

(3) No ambiguity

The description of the requirements should be objective and unambiguous. A requirement should be consistent with all readers' explanations, which are intended to be easy for the stakeholders to understand, especially for easy understanding of the client in order to avoid errors.

(4) Feasibility

Demand should be in line with the existing development conditions, brand culture, business environment, with a certain "feasible." Where "viability" means technically feasible and satisfies constraints such as time, cost, quality

(5) Verifiability

Each requirement can be verified by designing a test case or other verification method, such as a demonstration, to guide the next job. The

(6) Can be modified

Each requirement item is uniquely identified, and the grouping of the requirements is identified and the history of the change is recorded so that it is easy to modify and maintain consistency.

(7) Can be tracked

In each of the requirements and the realization of the requirements of the design components, 
development components, test cases to establish a link between, so that two-way traceability can be tracked.

(8) Has priority

\section{Conclusions}

Planning is customer-centric, to the development as the goal, based on mutual benefit to communicate tree image of the overall product planning, and consumers and the market is the most intimate link, the success or failure of the product's best-selling or not. At present, although the planning of China's garment enterprises is still in the growth stage, but gratifying is more and more enterprises aware of the planning of the pivotal position, planning departments are also exploring the continuous improvement and improvement in some of the more successful enterprises, the role of the role is also constantly confirmed with sales data. Grasp the needs of the target market, correctly transform the demand for the product, play the strategic significance of planning, the relationship between the future and fate of enterprises to ensure that enterprises occupy more market share and help enterprises in the fierce domestic and foreign markets in an undefeated position.

\section{References}

[1] Hauser JR,Clausing D.The house of quality. Harvard Business . 1988

[2] PATRICIA Seybold,RONNI T Marshak,JEFFREY M Lewis. The customer revolution:how to thrive when customers are in control. Journal of Consumer Marketing . 2002

[3] Henning Gebert,Malte Geib,Lutz Kolbe,Walter Brenner. Knowledge-enabled customer relationship management: integrating customer relationship management and knowledge management concepts [J]. Journal of Knowledge Management . 2003 